\section{THE RECENT AURORA, AND A NEW FORM OF DECLINOMETER}

N Sunday night, the $4^{\text {th }}$ of February, we saw here the magnificent coloured Aurora Borealis, which has been described in NATURE, in the newspapers, and which, I see from telegrams, has been observed at very distant stations. Indications of the aurora were noticed here soon after sunset; but about 6.45 P.M. the whole eastern portion of the sky became illuminated with red light, at first faint, but rapidly becoming more and more intense, while yellow streamers began to shoot up from the north-eastern arc of the horizon nearly to the zenith. About the south-west there was also much red and yellow light; it was spread over a large apparent area, but was not so intensely bright or so strongly coloured as that which lay to the north-east. It too, however, possessed splendid broad, yellow streamers. The display lasted in full beauty till about 7.20 , but long after that time much red and yellow light with occasional streamers was to be seen.

It is strange that the phenomena of the Aurora Borealis still remain so little understood. It would add much to our knowledge, if those who witness these displays would make sketches of the appearances at the time when very definite forms of the streamers are observed, noting also the time of the observation very carefully, and the position of well-known stars and constellations. A comparison of such sketches, and of notes that might accompany them, would give us most important data, and might lead to the determination of the locality of the discharge

Simultaneous observations, at widely different stations, of the disturbances of terrestrial magnetism that always accompanied the aurora might, if compared, give us useful information as to the direction and velocity of the electric discharge ; and would probably at least help us to decide whether it is to the discharges themselves, or to earthcurrents, or to both combined, that these disturbances are due.

I wish to describe an instrument planned by Sir William Thomson, which may be easily constructed, and with which the variations of the horizontal component of terrestrial magnetism can be determined with great accuracy.

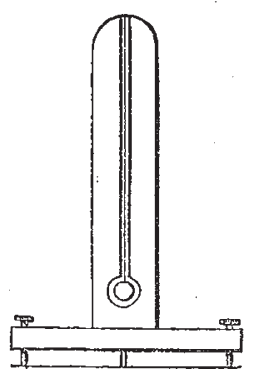

FIG. I
A flat wooden support, seven or eight inches high, is fixed on a convenient foot furnished with levelling scress, and in the face of it a groove, rather more than four inches long and about $i^{3}$ of an inch deep, is cut. From a point at the top of this groove, a very light mirror with magnets attached-such as is used in Thomson's reflecting galvanometer-is suspended by a single silk fibre about four inches long; and in front of the groove there is fastened, if the mirror be concave, a slip of plate glass to keep off currents of air : or, if it be a plane mirror, a lens is fastened in front of it, and the remainder of the groove is covered up with a slip of glass or in some other way. A lamp is placed in front of the mirror, and the reflected image of it is received on a scale. The motions of the reflected light upon the scale indicate the deflections of the magnet.

Suitable mirrors and lenses are constructed by Mr. White, instrument maker, Glasgow. In making the mirrors, a large number of the lightest circular glasses used for covering objects on slides for the microscope are silvered; and from these those which give an image perfectly free from distortion are selected by trial. Many of the mirrors formed are much twisted and quite unfit for us 2 ; but mirrors are obtained by this plan of selection by trial far superior in lightness and in freedom from distortion to any that can be made by expending extreme care in the glass-work. To the back of each mirror four small magnets are attached; an arrangement which has been found by trial to give the best result. The object is to make the mirror with its magnets suffi. ciently light, and to give it at the same time the greatest possible magnetic moment. The mirror is three-eighths of an inch in diameter, and weighs not more than onethird of a grain.

Plane mirrors are generally used in Glasgow, and the lens is of such power that a lamp placed at a distance of one metre (about 40 inches) gives an image at the same distance from the mirror. The lamp is placed behind a screen, and in the screen an oval hole is cut and a vertical wire* is stretched across it. The image of this wire is received upon a scale. The scale may be set at a distance of 40 inches (one metre) from the mirror; that is to say it

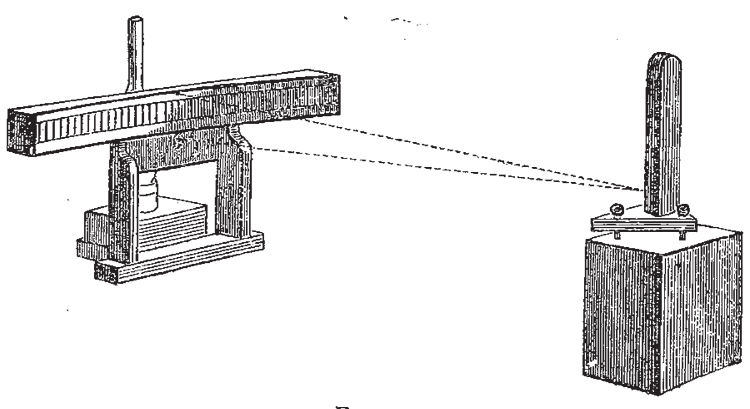

FIG. 2

may be attached to the screen between the mirror and the lamp ; or it may be put much farther away, at, say two or three times that distance. The lamp and screen, with its slit and wire, must then be brought near enough to the mirror to throw back the conjugate focus sufficiently. This arrangement gives of course increased sensibility. We use for it 3 paraffin oil lamp, of which the reservoir is a very shallow rectangular vessel. The slit in the screen is slightly above the horizontal plane through the centre of the mirror, and the scale slightly below that plane. The reflected ray passes below the reservoir of the lamp to the scale beyond.

Our scales, which are also obtainable from Mr. White, are divided into fortieths of an inch, and are generally attached to a piece of wood, cut out so that its curvature corresponds to that of a circle described with the distance of the mirror as radius. Thus, by dividing the number of scale divisions by the distance of the mirror in fortieths of an inch from the scale, the angle is obtained to which that number of scale divisions correspond. At a distance of 60 inches we can easily read the position of the image of the wire on the scale to less than half a scale division, which, since the angle turned through by the reflected beam of light is twice that turned through by the mirror, corresponds to an angular deflection of about $20^{\prime \prime}$.

The great, advantage which the arrangement that I have just described possesses over any that are ordinarily used for observing rapid variation in magnetic declination lies in the lightness of the mass moved. The heavy declinometers employed in observatories are unable, through their great inertia, to follow accurately the sudden variations that occur during a magnetic storm.

The College, Glasgow

JAMES THOMSON BOTTOMLEY

* A simple vertical slit was formerly used, but the vertical wire in the middle of the slit, a suggestion of Prof. 'Tait, is a great improvement, as it enakles us to use plenty of light, while it gives increased precision to the reading on the scale. 